\title{
Randomized comparison of two methods of the epidural space identification during regional labour analgesia
}

\author{
Larysa Duniec ${ }^{1,2}$, Jan Bilawicz, ${ }^{1,2}$, Marcin Chlebus ${ }^{3}$, Bronislawa Pietrzak ${ }^{1}$, Miroslaw Wielgos ${ }^{1}$ \\ ${ }^{1} 1$ st Chair and Department of Obstetrics and Gynecology, Medical University of Warsaw, Poland \\ 2I Department of Anaesthesiology and Intensive Care, Medical University of Warsaw, Poland \\ ${ }^{3}$ Department of Quantitative Finance, Faculty of Economic Sciences, University of Warsaw, Poland
}

\begin{abstract}
Objectives: Conventional loss of resistance (LOR) technique for identifying the epidural space (EDS) predominantly depends on experience of the anaesthetist. A technique using automated syringe for EDS identification was invented as an alternative to the traditional method. The aim of the study was to compare the efficacy and risk for complications between automatic LOR syringe - Epimatic ${ }^{\circledast}$ (Vygon, Ecouen, France) and conventional LOR — Perifix ${ }^{\circledast}$ (B.Braun Melsungen AG, Melsungen, Germany) techniques for EDS identification.

Material and methods: A total of 170 patients were enrolled into the study and 153 cases were analysed. Number of attempts, time to EDS identification, ease of EDS identification, complication rate and patient procedure-related discomfort were evaluated and compared.

Results: No statistically significant differences were found in the number of needle insertion attempts (1.3 in both groups), time to EDS identification (31 sec. vs. $27 \mathrm{sec}$.), efficacy of epidural analgesia (100\% in both groups), or complication rate between both groups.

Conclusions: The automatic and the conventional LOR techniques are comparable in terms of efficacy and safety for the epidural space identification.

Key words: epidural analgesia; epidural space; loss-of-resistance technique; automatic identification; labour analgesia
\end{abstract}

Ginekologia Polska 2019; 90, 5: 279-284

\section{INTRODUCTION}

Lumbosacral epidural analgesia (EDA) remains the most effective way of alleviating labour pain [1], as it increases patient comfort and quality of patient-personnel cooperation during labour. The procedure involves 3 crucial steps: (i) identification of vertebrae level, (ii) selection of desired puncture site and angle, (iii) needle insertion into epidural space (EDS) between ligamentum flavum (LF) and dura mater covering a spinal cord [2].

Identification of EDS, which has only several millimetres, is the key element and the necessary prerequisite of effective EDA [2]. The fact that there is negative pressure within the epidural space is clinically important $[3,4]$. Negative pressure can be magnified by increased flexion and reduced by decreased flexion of the spine [5]. Several techniques detecting a change in the resistance or pressure have been proposed for EDS identification: a dual technique [6], balIoon technique [4], drip infusion technique [4], acoustic signalization $[7,8]$ Despite the claimed advantages, none of them is widely used in clinical practice [8].

The current gold standard is the loss of resistance (LOR) technique described in 1921 by Pages [6]. However, regardless of saline or air usage, it is associated with a significant failure rate of up to $32 \%$ and may be time-consuming [9-11]. It remains a particular change among pregnant women due to impaired palpability of anatomical landmarks and flawed identification of the entry to EDS - as ligament complex (supraspinous ligament, interspinous ligament, ligamentum flavum) become softer and more inhomogeneous, which may mimic the feeling of lost resistance. It is happening 


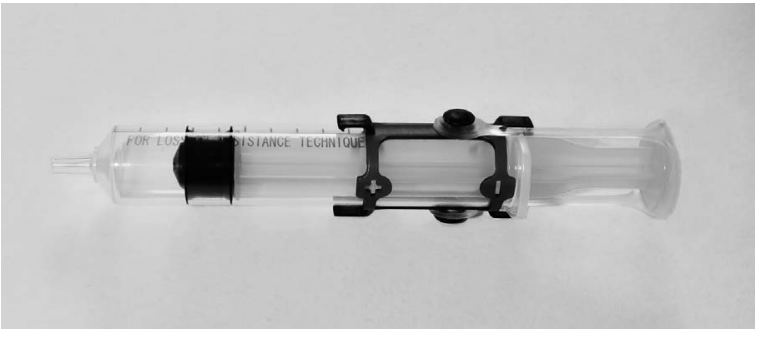

Figure 1. Epimatic ${ }^{\circledast}$ syringe

because of increased relaxin and estrogen levels, which change the ligament structure and the fact that ligaments are bearing greater burden due to $15-20 \mathrm{~kg}$ weight, gain [12]. Moreover, epidural pressure during pregnancy is elevated secondary to increased oedema, elevated vena cava inferior and intreperitoneal pressure and enlarged venous plexus [13]. However, the blind technique may lead to accidental dural puncture with a following post-procedural headache as well as accidental plexus venous puncture [5, 6].

Thus, the search for a simple, objective, effective, safe and reliable method of EDS localization has been underway for many years, with the automatic Epimatic ${ }^{\circledR}$ syringe (Vygon) as an example of a tool for EDS identification (Fig. 1). Epimatic ${ }^{\circledast}$ is a low-resistance syringe where continuous positive pressure on the plunger is achieved by an elastic strip. When the Tuohy needle enters the epidural space, LOR is visible by the sudden movement of the syringe plunger, which removes operator subjectivity and variability [14]. The other advantage of the spring-loaded syringe is that both hands can be used for needle's advance and stabilization [15].

\section{Objectives}

The aim of the study was to compare the effectiveness and complications of EDS identification with the use of conventional LOR technique and the automatic syringe system during EDA.

\section{MATERIAL AND METHODS}

This manuscript adheres to the applicable EQUATOR guidelines [16]. The study was a prospective, single-blinded, randomized study conducted in one centre between January and September 2015. Prior to the study onset, a randomization list was prepared based on the coin toss by Primary Investigator. Patients were blind and randomized according to the list to undergo standard EDA (control group) or Epimatic ${ }^{\circledR}$ syringe EDA (study group).

Inclusion criteria were (i) patient's choice of EDA during labour and (ii) informed consent to participate in the study. Exclusion criteria were following clinical contraindications for EDS: (i) skin lesion at the puncture area, (ii) coagulopathy, (iii) lack of informed consent to participate in the study.
All the procedures were following standard preparation for the neuraxial block with life sign's monitoring. EDA was performed in sitting or lateral position at the preference of the one out of four study anaesthetist, each with at least 10 years of clinical experience. For epidural space identification during LOR technique, all of them preferred air to be used.

In both groups, total aseptic technique was used, the appropriate intervertebral space was identified, and lidocaine (Lignocainum hydrochloricum WZF 1\% $2 \mathrm{~mL}$, Polfa Warszawa SA) was administered as local analgesia for the skin and the subcutaneous tissue, a Tuohy needle was inserted and attached to the automatic or conventional syringe. The needle was positioned and pushed towards the ED space until LOR was felt (conventional method) or plunger movement was observed (automatic method), thus confirming entry into the epidural space.

In the control group, EDA was performed using the Perifi ${ }^{\circledast}$ kit (B.Braun Melsungen AG, Melsungen, Germany) — including a Tuohy Perican ${ }^{\circledR} 18 \mathrm{G}$ epidural needle (diameter: $1.3 \mathrm{~mm}$, length: $80 \mathrm{~mm}$ ) and a Perifix ${ }^{\circledR}$ LOR syringe with continuous pressure applied by the anesthetist using his/her thumb. The syringe was filled with air. In the study group, a Tuohy Perican ${ }^{\circledR} 18 \mathrm{G}$ epidural needle (diameter: $1.3 \mathrm{~mm}$, length: $80 \mathrm{~mm}$ ) and an Epimatic ${ }^{\circledR}$ syringe (Vygon, Ecouen, France), filled with air, were used.

After EDA procedure and delivery, each patient was followed-up for 24 hours.

The principal aim of our study was to establish the efficacy of Epimatic ${ }^{\circledast}$ syringe and to estimate rates of complications in each group. Therefore, the number of randomized patients (170) was not selected to power any hypothesis test, but to provide the most accurate estimation of population rates giving the time and resources available. The following criteria were used for comparative assessment:

- patient's demographic and anthropometric data: age, height, BMI, primiparous/multiparous status;

- procedural data: positioning, LOR depth, number of puncture attempts until EDA, time to EDA, time to LOR feeling;

- operator's views: ease of catheterization;

- patient's view: level of discomfort during the procedure, procedural efficacy scored in Numerical Rating Scale (NRS), satisfaction measured by willingness to undergo the same procedure in the future;

- post-procedural complications: regional pain, skin irritation/redness, accidental dural puncture (ADP), accidental catheterization of epidural venous plexus.

Local Ethics Committee approved of the study (no. $K B / 226 / 2014)$. Each participant signed informed consent.

\section{STATISTICAL ANALYSIS}

A total of 170 patients without contraindications to neuraxial analgesia, who received EDA during labour, were included in the study (Fig. 2). 


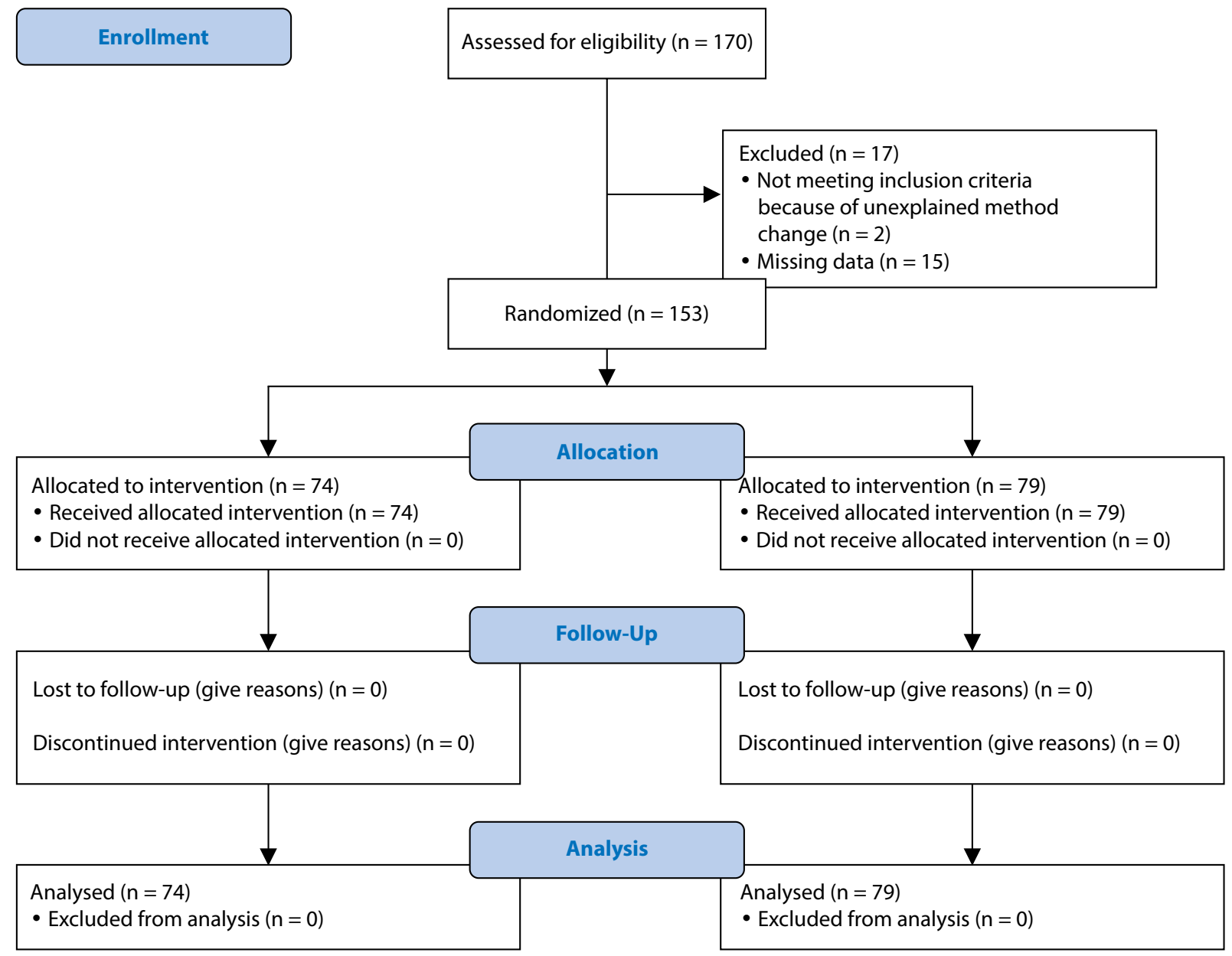

Figure 2. CONSORT 2010 Flow diagram of the progress through the phases of a parallel, ranodomised trial of two groups (enrolment, intervention allocation, follow-up, data analysis)

In case of continuous dependent variables, two-sample one-sided t-Student test was used to compare the differences in means between two independent groups (sample size of $>30$ for both groups allows to use the central limit theorem). Fisher's test was used to verify equality of variances of the investigated variables. Additionally, $\mathrm{Chi}^{2}$ Pearson's test and Fisher's exact test were used to compare distributions of categorical dependent variable between the independent groups [17]. In case of multiple regression analysis, depending on the specificity of the analyze variable, one of the following three models was used: linear regression (continuous distribution variables), logit regression (dichotomous outcome variables), or Poisson regression (set of natural numbers distribution variable) [18]. The $p$-value of $<0.05$ was considered as statistically significant.

\section{RESULTS}

A total of 170 patients were randomized for the study and 153 women were evaluated. Their baseline characteristics are presented in the Table 1.

\begin{tabular}{|c|c|c|c|}
\hline Parameter & $\begin{array}{l}\text { Perifix } \\
(n-74)\end{array}$ & $\begin{array}{l}\text { Epimatic }{ }^{\circ} \\
(\mathrm{n}-79)\end{array}$ & $\mathbf{p}$ \\
\hline Age [years] & $30.95(4.56)$ & $30.51(4.42)$ & 0.27 \\
\hline Height $[\mathrm{cm}]$ & $167.18(4.43)$ & $165.71(6.70)$ & 0.06 \\
\hline BMI & $28.11(3.80)$ & $27.26(3.74)$ & 0.08 \\
\hline Primiparous & $44(59 \%)$ & 58 (73\%) & $0.067^{*}$ \\
\hline Multiparous & 30 (41\%) & 21 (27\%) & $0.086^{* *}$ \\
\hline
\end{tabular}

${ }^{*}$ Chi ${ }^{2}$ Pearson's test; ${ }^{* *}$ Fischer's exact test

Data on maternal position during epidural analgesia are presented in Table 2. No statistically significant differences between the modes of identification were found.

Data on the procedure-related parameters are presented in Table 3. No statistically significant differences between the two methods were found.

No statistically significant differences in tactile sensation of resistance loss felt by the anesthetist performing the pro- 


\begin{tabular}{l|l|l|l|l|}
\hline \multicolumn{2}{|l|}{ Table 2. Maternal position during epidural analgesia } \\
\hline \multirow{2}{*}{ Parameter } & $\begin{array}{l}\text { Perifix } \\
(\mathbf{n}-74)\end{array}$ & $\begin{array}{l}\text { Epimatic } \\
\text { (n -79) }\end{array}$ & p \\
\hline $\begin{array}{l}\text { Mode of } \\
\text { identification }\end{array}$ & lateral & $2(2.78 \%)$ & $4(5.26 \%)$ & $0.444^{*}$ \\
& sitting & $70(97.22 \%)$ & $72(94.74 \%)$ & $0.682^{* *}$ \\
\hline & no data & 2 & 3 & \\
\hline
\end{tabular}

*Chi ${ }^{2}$ Pearson's test; **Fischer's exact test

\begin{tabular}{|l|l|l|l|}
\hline \multicolumn{3}{|l|}{ Table 3. Data on the EDA procedure in both groups } \\
\hline Parameter & $\begin{array}{l}\text { Perifix } \\
(\mathbf{n}-\mathbf{7 4 )}\end{array}$ & $\begin{array}{l}\text { Epimatic }^{\circledR} \\
(\mathbf{n}-\mathbf{7 9 )}\end{array}$ & $\mathbf{p}$ \\
\hline LOR depth [cm] & $6.13(0.95)$ & $5.88(0.79)$ & 0.074 \\
\hline $\begin{array}{l}\text { Puncture attempts until } \\
\text { EDA [number] }\end{array}$ & $1.29(0.68)$ & $1.29(0.67)$ & 0.962 \\
\hline Time to EDA [s] & $47.32(45.48)$ & $53.13(45.05)$ & 0.436 \\
\hline Time to feeling of LOR [s] & $26.59(37.33)$ & $31.48(38.18)$ & 0.492 \\
\hline
\end{tabular}

\begin{tabular}{|c|c|c|c|}
\hline Parameter & $\begin{array}{l}\text { Perifix } \\
(n-74)\end{array}$ & $\begin{array}{l}\text { Epimatic }{ }^{\circledR} \\
(n-79)\end{array}$ & $\mathbf{p}$ \\
\hline Very easy & $1(1.37 \%)$ & $1(1.35 \%)$ & \multirow{4}{*}{0.096} \\
\hline Easy & $61(83.56 \%)$ & $68(91.89 \%)$ & \\
\hline Slight resistance & $11(15.07 \%)$ & $5(6.76 \%)$ & \\
\hline No data & 1 & 5 & \\
\hline
\end{tabular}

\begin{tabular}{|l|l|l|l|}
\hline \multicolumn{4}{|c|}{ Table 5. Level of patient discomfort during the procedure } \\
\hline Discomfort & $\begin{array}{l}\text { Perifix } \\
(\mathbf{n}-74)\end{array}$ & $\begin{array}{l}\text { Epimatic }^{\circledR} \\
(\mathbf{n}-79)\end{array}$ & p \\
\hline None & $35(48.61 \%)$ & $34(45.33 \%)$ \\
\hline Slight & $37(51.39 \%)$ & $40(53.33 \%)$ & 0.539 \\
\hline Significant & $0(0 \%)$ & $1(1.33 \%)$ & \\
\hline No data & 2 & 4 & \\
\hline
\end{tabular}

cedure were found. Ease of catherization was comparable in both groups (Tab. 4).

The level of patient discomfort during the procedure did not differ significantly between the groups and was reported by the majority of patients to be 'slight' or 'none' (Tab. 5).

Mean pre-epidural NRS score was $>7$ points in both groups and no statistically significant differences were found. Mean post-epidural NRS scores were 2 and 2.3 points in the Epimatic ${ }^{\circ}$ and Perifix ${ }^{\circ}$ groups, respectively and no statistically significant differences were found (Tab. 6).

As for future consent for repeat procedure, $98.7 \%$ and $98.61 \%$ of the women from the Epimatic ${ }^{\oplus}$ and the Perifix ${ }^{\circledast}$ groups declared they would consent to the procedure again (Tab. 7). No statistically significant differences were found.

\begin{tabular}{|l|l|l|l|}
\hline \multicolumn{3}{|l|}{ Table 6. Pain assessment using Numerical Rating Scale (NRS) } \\
\hline $\begin{array}{l}\text { Pain assessment using } \\
\text { NRS }\end{array}$ & $\begin{array}{l}\text { Perifix } \\
(\mathbf{n}-74)\end{array}$ & $\begin{array}{l}\text { Epimatic }^{\oplus} \\
(\mathbf{n}-79)\end{array}$ & p \\
\hline Pre-epidural NRS & $7.66(0.82)$ & $7.63(0.89)$ & 0.724 \\
\hline Post-epidural NRS & $2.3(1.38)$ & $2(0.45)$ & 0.062 \\
\hline
\end{tabular}

\section{Table 7. Declaration of future consent to epidural analgesia}

\begin{tabular}{|l|l|l|l|}
\hline Parameter & $\begin{array}{l}\text { Perifix } \\
\text { (n-74) }\end{array}$ & $\begin{array}{l}\text { Epimatic }^{\oplus} \\
\left(\mathbf{n}-\mathbf{7 9}^{-}\right.\end{array}$ & $\mathbf{p}$ \\
\hline Yes & $71(98.61 \%)$ & $74(98.67 \%)$ & $0.977^{*}$ \\
\hline No & $0(0 \%)$ & $0(0 \%)$ & $1.00^{* *}$ \\
\hline Other & $1(1.39 \%)$ & $1(1.33 \%)$ & \\
\hline No data & 2 & 4 & \\
\hline
\end{tabular}

${ }^{*}$ Chi ${ }^{2}$ Pearson test ${ }^{* *}$ Fischer's exact test

\begin{tabular}{|c|c|c|c|}
\hline Parameter & $\begin{array}{l}\text { Perifix } \\
(n-74)\end{array}$ & $\begin{array}{l}\text { Epimatic }^{\oplus} \\
(\mathbf{n}-79)\end{array}$ & $p$ \\
\hline None & $22(30.14 \%)$ & $25(33.33 \%)$ & 0.675 \\
\hline Regional pain & $48(65.75 \%)$ & $43(57.33 \%)$ & 0.272 \\
\hline Skin irritation (redness) & $3(4.11 \%)$ & $7(9.33 \%)$ & 0.216 \\
\hline $\begin{array}{l}\text { Accidental dural puncture, } \\
\text { ADP }\end{array}$ & $0(0 \%)$ & $0(0 \%)$ & ND \\
\hline $\begin{array}{l}\text { Accidental catheterization } \\
\text { of epidural venous plexus }\end{array}$ & $2(2.7 \%)$ & $3(3.8 \%)$ & 0.702 \\
\hline
\end{tabular}

The most common EDS analgesia-related complication was regional pain. Local redness at the puncture site were also reported, although less often. No statistically significant differences in terms of complication rates were found between both groups (Tab. 8).

\section{DISCUSSION}

There is one study available in the literature comparing Epimatic ${ }^{\oplus}$ syringe and conventional LOR technique conducted by Dilish et al [19], which included 40 patients undergoing lumbar epidural anesthesia with no specified procedure type. In contrast to our study, they reported on significantly shorter time to identify the epidural space ( 8 vs. 35 seconds, respectively, $\mathrm{p}<0.001)$ and a difference between the number of attempts ( 1.25 vs. 1.6 , respectively). Similarly to our results, there was no statistically significant difference between groups in regards to the easiness of catheter insertion. There was one accidental dural puncture in the control group [19]. 
The literature offers reports on 3 other syringes with a similar mechanism of action (constant positive-pressure for the automated EPD identification), namely (i) Episure ${ }^{\mathrm{TM}}$ AutoDetect ${ }^{\mathrm{TM}}$ syringe, Indigo Orb, Inc., Santa Clara, California, United States [14, 15, 20-22] (ii) Epidrum, Emooor Innovations Ltd. Taunton, United Kingdom [13, 22-28] and (iii) Epi-Jet, Egemen International, Izmir, Turkey [13, 29].

Our study found no difference for the primary outcome, namely the efficacy of EDA measured by NRS. In the literature, the failed analgesia was defined in the study by Habib [21] and Joseph [14] as a need to resit needle due to the failure to obtain sensory blockade after the initial drug dosage and occurred significantly less often in the the Episure ${ }^{\mathrm{TM}}$ group compared to controls (0\% vs. 3.2\%; $0 \%$ vs.8.3\% respectively). However, findings from Deighan et al. [23] on Epidrum reports on the higher rate of failed analgesia ( $6 \%$ vs. $0 \%$ ).

Similarly to our study, the majority of studies reported no difference between the number of puncture attempts between the automated and the conventional group $[13,15,28,29]$. The remaining revealed lower number for the automated groups, in the study of Episure ${ }^{\mathrm{TM}}$ the efficacy of the first attempt was $91.6 \%$ vs. $76.6 \%$ [14] and in the study of Epidrum less than 2 attempts were needed more often for Epidrum (96.3\% vs. 85.9\%) [25]. Kim et al. [25] defined the procedural failure as the need of more than 4 needle insertion attempts. Their study reported that this outcome was less often in the Epidrum group compared to controls (0\% vs. 9.25\%) [25].

In our study, time to EDA was slightly shorter in the study group as compared to controls $(53 \mathrm{sec}$. vs. $47 \mathrm{sec}$., respectively), but the difference was not statistically significant. However, the literature does not confirm this finding. Episure ${ }^{\mathrm{TM}}$ is characterized by quicker EDA achievement (32 vs. 39 s) [14], similarly to Epidrum (18.6 vs. 31.5 s) [25]. Findings on Epi-jet are at odds, which may be caused by an operator's experience $[13,29]$.

Patient satisfaction with the procedure, defined as consent to the same method in the future, was reported by the vast majority of the women (98.6\%) and was comparable in both groups. Other authors did not investigate that parameter.

Our results stated that $93.24 \%$ of operators found the procedure easy/very easy in the Epimatic ${ }^{\circ}$ group and $84.83 \%$ in the control group, however, those results did not reach statistical significance most probably to the insufficient sample size. In the literature operator's satisfaction was always higher in the automated syringe group [13, 15, 28, 29], except for Epidrum in contrast to control group in the study by Kartal et al. [13] (60.3\% vs. $73.8 \%)$.

There is the scarcity of information on complication rates in the literature. The accidental dural puncture (ADP) was reported most common. Similar to our study, Riley et al. [15] and Demirel et al. [29] reported on the lack of this complication. The remaining studies revealed that the side effect appeared less commonly in the automated syringe group $[14,21,22,25]$. Only one study by Habib et al. [21] reported on accidental puncture of the venous plexus, which appeared insignificantly more often in the Episure ${ }^{\mathrm{TM}}$ group (5.4\% vs. $4.5 \%$ ). Moreover, an automatic syringe might be applicable for an ultrasound-guided neuraxial block as it allows the anaesthetist to manipulate the ultrasound transducer, requiring the use of only one hand for needle insertion. It has been proven that ultrasound pre-scanning increases first-pass success and decreases the number of needle passes $[9,30]$.

Additionally, an automatic syringe gives a unique opportunity for an objective assessment by the teacher during procedure conduct by a younger Colleague, which is not possible with the conventional LOR technique [21, 24].

\section{Study limitations}

This study has several limitations. First, the study was not planned as double-blinded research because of the impossibility of using the device without operator knowledge. Secondly, the sample size was moderate and not estimated to power the hypothesis testing. Furthermore, our study was conducted by the experienced anaesthesiologist - however, the low learning curve [20] and studies with residents [21] suggest that results may be applicable for less experienced practitioners. There may be an operator bias. Moreover, we identified epidural space within lumbar level and results may not be extrapolated to other vertebral segments.

\section{CONCLUSIONS}

1. Safety and efficacy of EDS identification are comparable in both methods.

2. Both methods of EDS identification may be successfully applied in patients during labour analgesia.

\section{Conflict of interests}

The authors have no conflict of interest to declare.

\section{Financial disclosure}

The cost of syringes was covered using the authors' own research budget.

\section{REFERENCES}

1. Cambic CR, Wong CA. Labour analgesia and obstetric outcomes. B J Anaesth. 2010; 105 Suppl 1:i50-i60, doi: 10.1093/bja/aeq311, indexed in Pubmed: 21148655

2. Rafii-Tari H, Lessoway VA, Kamani AA, et al. Panorama Ultrasound for Navigation and Guidance of Epidural Anesthesia. Ultrasound Med Biol. 2015; 41(8): 2220-2231, doi: 10.1016/j.ultrasmedbio.2015.03.012, indexed in Pubmed: 25964065.

3. Hughes SC, Levinson G, Rosen MA, Shnider SM. Shnider and Levinson's anesthesia for obstetrics - Maternal Physiologic Alterations during pregnancy. Lippincott Williams \& Wilkins 2002. 
4. Kaur K, Singhal S, Bala M. Identification of epidural space using loss of resistance syringe, infusion drip, and balloon technique: A comparative study. Saudi Journal of Anaesthesia. 2014; 8(5): 41, doi: 10.4103/1658354x.144070.

5. Fyneface-Ogan S. Anatomy and Clinical Importance of the Epidural Space. In: Epidural Analgesia - Current Views and Approaches. InTechOpen 2012.

6. Jacob S, Tierney E. A dual technique for identification of the epidural space. Anaesthesia. 1997; 52(2): 141-143, indexed in Pubmed: 9059097.

7. Teng WN, Tsou MY, Chang WK, et al. Eyes on the needle: Identification and confirmation of the epidural space. Asian J Anesthesiol. 2017; 55(2): 30-34, doi: 10.1016/j.aja.2017.05.009, indexed in Pubmed: 28971802.

8. LechnerTJM, van Wijk MGF, Maas AJJ. Clinical results with a new acoustic device to identify the epidural space. Anaesthesia. 2002; 57(8): 768-772, indexed in Pubmed: 12133089.

9. Elsharkawy H, Sonny A, Chin KiJ. Localization of epidural space: A review of available technologies. J Anaesthesiol Clin Pharmacol. 2017; 33(1): 16-27, doi: 10.4103/0970-9185.202184, indexed in Pubmed: 28413269.

10. Samhan YM, El-Sabae HH, Khafagy HF, et al. A pilot study to compare epidural identification and catheterization using a saline-filled syringe versus a continuous hydrostatic pressure system. J Anesth. 2013; 27(4): 607-610, doi: 10.1007/s00540-013-1567-y, indexed in Pubmed: 23408046.

11. Antibas PL, do Nascimento Junior $P, B r a z ~ L G$, et al. Air versus saline in the loss of resistance technique for identification of the epidural space. Cochrane Database Syst Rev. 2014(7):CD008938, doi: 10.1002/14651858. CD008938.pub2, indexed in Pubmed: 25033878.

12. Schröder G, Kundt G, Otte M, et al. Impact of pregnancy on back pain and body posture in women. J Phys Ther Sci. 2016; 28(4): 1199-1207, doi: 10.1589/jpts.28.1199, indexed in Pubmed: 27190453.

13. Kartal S, et al. Comparison of Epidrum, Epi-Jet, and Loss of Resistance syringe techniques for identifying the epidural space in obstetric patients. Niger. J. Clin. Pract. 2017; 20(8): 992-997.

14. Joseph EJ, Pachaimuthu E, Arokyamuthu V, et al. Comparative study of Episure $^{\mathrm{TM}}$ AutoDetect ${ }^{\mathrm{TM}}$ syringe versus glass syringe for identification of epidural space in lower thoracic epidural. Indian J Anaesth. 2015; 59(7): 406-410, doi: 10.4103/0019-5049.160933, indexed in Pubmed: 26257412.

15. Riley ET, Carvalho B. The Episure syringe: a novel loss of resistance syringe for locating the epidural space. Anesth Analg. 2007; 105(4): 1164-6, table of contents, doi: 10.1213/01.ane.0000281935.78144.82, indexed in Pubmed: 17898406.

16. Moher D, et al. CONSORT 2010 Explanation and Elaboration: updated guidelines for reporting parallel group randomised trials. J. Clin. Epidemiol. 2010; 63(8): e1-e37.
17. Zelterman L, Louis T. Medical uses of statistics - Contingency tables in medical studies, 3rd ed. John Wiley \& Sons 2009.

18. Jones AM. Applied econometrics for health economists: a practical guide.

19. Dilish G., Murugesan K., Jayasree R.. Comparison of techniques- identification of epidural space using the loss of resistance syringe and an automated syringe. Journal of Evolution of Medical and Dental Sciences. 2017; 6(80): 5657-5660, doi: 10.14260/jemds/2017/1226.

20. Carabuena J, Mitani A, Liu X, et al. The Learning Curve Associated with the Epidural Technique Using the Episure ${ }^{\mathrm{TM}}$ AutoDetect ${ }^{\mathrm{TM}}$ Versus Conventional Glass Syringe. Anesthesia \& Analgesia. 2013; 116(1): 145-154, doi: 10.1213/ane.0b013e31826c7cad.

21. Habib AS, George RB, Allen TK, et al. A Pilot Study to Compare the EpisureTM AutodetectTM Syringe with the Glass Syringe for Identification of the Epidural Space in Parturients. Anesth. Analg. 2008; 106(2): 541-543.

22. Paech MJ, Muchatuta NA, Griffiths JD, et al. The Episure loss-of-resistance syringe. Anaesth Intensive Care. 2011; 39(5): 976, indexed in Pubmed: 21970154

23. Deighan $\mathrm{M}$, Briain DO, Shakeban $\mathrm{H}$, et al. A randomised controlled trial using the Epidrum for labour epidurals. Ir Med J. 2015; 108(3): 73-75, indexed in Pubmed: 25876297.

24. Hirabayashi T, et al. Usefulness of Epidrum for teaching identification of the epidural space. Masui. 2011; 60(9): 1078-1081.

25. Kim SW, Kim YMi, Kim SH, et al. Comparison of loss of resistance technique between Epidrum ${ }^{\oplus}$ and conventional method for identifying the epidural space. Korean J Anesthesiol. 2012; 62(4): 322-326, doi: 10.4097/kjae.2012.62.4.322, indexed in Pubmed: 22558497.

26. Le Guen $M$, Charvet $A$, Leone $M$, et al. Epidrum is an unreliable device for identifying the thoracic epidural space. Eur J Anaesthesiol. 2018; 35(9): 716-717, doi: 10.1097/EJA.0000000000000810, indexed in Pubmed: 30063534.

27. Sawada A, Kii N, Yoshikawa $Y$, et al. Epidrum $\left({ }^{\oplus}\right)$ : a new device to identify the epidural space with an epidural Tuohy needle. J Anesth. 2012; 26(2): 292-295, doi: 10.1007/s00540-011-1278-1, indexed in Pubmed: 22081113.

28. Seog Sim W, et al. False Loss of Resistance in Cervical Epidural Injection: The Loss of Resistance Technique Compared with the Epidrum Guidance in Locating Epidural Space. Pain Physician. 2016; 19: 131-138.

29. Demirel A, et al. The Comparison of Loss of Resistance Technique, Automatic Loss of Resistance Syringe and Hanging Drop Technique for Identifying Epidural Space. Int. J. Pain Reli. 2017; 1(1): 32-35.

30. Grau T, Leipold RW, Horter J, et al. The lumbar epidural space in pregnancy: visualization by ultrasonography. Br J Anaesth. 2001; 86(6): 798-804, indexed in Pubmed: 11573586. 